\title{
Caracterização das práticas atuais da limpeza de tanques de refrigeração de leite na região do semiárido brasileiro
}

\author{
Characterization of the current cleaning practices of milk cooling tanks in the brazilian semi-arid \\ region
}

Caracterización de las prácticas actuales de limpieza de tanques de enfriamiento de leche en el semiárido de Brasil

Genifer Reis do Nascimento ORCID: https://orcid.org/0000-0001-9485-7256 Universidade Federal do Rio Grande do Norte, Brasil E-mail: genifereis@gmail.com

Adriano Henrique do Nascimento Rangel ORCID: https://orcid.org/0000-0002-2835-4156 Universidade Federal do Rio Grande do Norte, Brasil E-mail: adrianohrangel@yahoo.com.br Dayana Melo Torres

ORCID: https://orcid.org/0000-0002-9385-3234 Universidade Federal do Rio Grande do Norte, Brasil E-mail: dayana.torres@ifrn.edu.br Marciano Furukava

ORCID: https://orcid.org/ 0000-0002-2666-4556 Universidade Federal do Rio Grande do Norte, Brasil E-mail: marciano.furukava@ufrn.br

Luis Henrique Fernandes Borba ORCID: https://orcid.org/0000-0002-6122-1865 Universidade Federal do Rio Grande do Norte, Brasil E-mail: lborba99@yahoo.com

Danielle Cavalcanti Sales

ORCID: https://orcid.org/0000-0003-0230-3446 Universidade Federal do Rio Grande do Norte, Brasil E-mail: daniellecsales@ hotmail.com

Josimar Torres Gomes

ORCID: https://orcid.org/0000-0001-8930-3216 Universidade Federal do Rio Grande do Norte, Brasil E-mail: Josimartg@gmail.com

Luiz Fernando Canazaro Trindade

ORCID: https://orcid.org/0000-0001-8743-3703 Universidade Federal do Rio Grande do Norte, Brasil E-mail: trindade.lfc@gmail.com

Luis Medeiros de Lucena

ORCID: https://orcid.org/0000-0002-9059-2905 Universidade Federal do Rio Grande do Norte, Brasil E-mail: luis_lucenaquim@yahoo.com.br

Heloysa Aline Pinheiro Lopes

ORCID: https://orcid.org/0000-0001-7210-7104 Universidade Federal do Rio Grande do Norte, Brasil E-mail: heloysapinheiro@ufrn.edu.br

Taoane Uchoa de Araújo Borges ORCID: https://orcid.org/0000-0003-1595-7633 Universidade Federal do Rio Grande do Norte, Brasil E-mail: taoaneuchoa18@gmail.com

\section{Resumo}

O leite é um alimento altamente perecível e sua qualidade é imprescindível para o consumo humano. Diante disso, a fazenda leiteira deve empregar processos de refrigeração do leite e limpeza dos equipamentos de modo que conservem a qualidade do produto. O objetivo desse estudo foi caracterizar o conhecimento do responsável quanto às boas práticas de limpeza do tanque de refrigeração do leite, e avaliar a higienização desses equipamentos usados em fazendas leiteiras no semiárido do Rio Grande do Norte-RN. Foi aplicado um questionário em 27 fazendas leiteiras distribuídas em 14 
municípios do estado para o levantamento de dados sobre o conhecimento do responsável e a limpeza dos tanques. Os dados qualitativos e quantitativos foram analisados mediante cálculo de médias e desvio padrão e as diferenças foram obtidas pelo teste de Duncan. Dentre os 27 tanques, 50\% apresentaram escore de limpeza 3 (ruim), 33,3\% bom e 16,67\% muito bom. Sobre o conhecimento de limpeza dos tanques, e 51,86\% dos produtores apresentaram conhecimento muito bom ou bom, e 48,15\% conhecimento ruim. Apenas 25,93\% dos proprietários utilizam métodos de sanitização. Este trabalho pode constituir uma referência técnica, servindo de subsídio para avaliar os impactos ambientais e financeiros na execução da higienização de equipamentos na produção leiteira.

Palavras-chave: Higienização de tanques; Perdas econômicas; Propriedades leiteiras; Reuso da água; Sustentabilidade.

\begin{abstract}
Milk is a highly perishable food and its quality is essential for human consumption. Therefore, the dairy farm must employ processes for cooling milk and cleaning equipment in order to preserve the quality of the product. The objective of this study was to characterize the knowledge of the person responsible for good practices for cleaning the milk cooling tank, and to evaluate the hygiene of this equipment used in dairy farms in the semiarid region of Rio Grande do Norte$\mathrm{RN}$. A questionnaire was applied in 27 dairy farms distributed in 14 municipalities in the state to collect data on the knowledge of the person responsible and the cleaning of the tanks. Qualitative and quantitative data were analyzed by calculating means and standard deviations and differences were obtained using Duncan's test. Among the 27 tanks, $50 \%$ had a cleaning score of 3 (poor), 33.3\% good and $16.67 \%$ very good. About the knowledge of cleaning the tanks, $51.86 \%$ of the producers had very good or good knowledge, and $48.15 \%$ had bad knowledge. Only $25.93 \%$ of owners use sanitation methods. This work can constitute a technical reference, serving as a subsidy to evaluate the environmental and financial impacts in the execution of the cleaning of equipment in milk production.
\end{abstract}

Keywords: Tank sanitation; Economic losses; Dairy properties; Water reuse; Sustainability.

\title{
Resumen
}

La leche es un alimento altamente perecedero y su calidad es fundamental para el consumo humano. Por lo tanto, la granja de productos lácteos debe emplear procesos de enfriamiento de la leche y equipos de limpieza con el fin de preservar la calidad del producto. El objetivo de este estudio fue caracterizar el conocimiento del responsable de las buenas prácticas para la limpieza del tanque de enfriamiento de la leche, y evaluar la higiene de estos equipos utilizados en las granjas lecheras de la región semiárida de Rio Grande do Norte-RN. Se aplicó un cuestionario en 27 vaquerías distribuidas en 14 municipios del estado para recolectar datos sobre el conocimiento del responsable y la limpieza de los tanques. Los datos cualitativos y cuantitativos se analizaron mediante el cálculo de medias y las desviaciones estándar y las diferencias se obtuvieron mediante la prueba de Duncan. Entre los 27 tanques, el 50\% tuvo una puntuación de limpieza de 3 (mala), el 33,3\% buena y el 16,67\% muy buena. Sobre el conocimiento de la limpieza de los tanques, el 51,86\% de los productores tenía muy buen o buen conocimiento y el 48,15\% tenía mal conocimiento. Solo el 25,93\% de los propietarios utilizan métodos de saneamiento. Este trabajo puede constituir un referente técnico, sirviendo como un subsidio para evaluar los impactos ambientales y financieros en la ejecución de la limpieza de equipos en la producción de leche.

Palabras clave: Saneamiento de tanques; Perdidas economicas; Propiedades lácteas; Reutilización de agua; Sustentabilidad.

\section{Introdução}

O leite é um produto agroindustrial ao qual sua produção é distribuída em diferentes atividades e segmentos da economia; essa cadeia produtiva, promove significativos impactos positivos na sociedade tais como o fortalecimento da autonomia econômica local, além da geração de empregos e impostos (ANUALPEC, 2019; FAO, 2017). A produção leiteira ocorre em todas as regiões do Brasil, com heterogeneidade de sistemas produtivos, que exploram o potencial de diferentes raças, com diferentes manejos, nível tecnológico e produtividade (Eurich et al., 2016). Assim também ocorre na região semiárida brasileira, onde se encontram estabelecimentos agropecuários leiteiros com diferentes níveis de produção e eficiência produtiva (Campos et al., 2016; Araújo et al., 2018).

Os sistemas de produção de leite brasileiros adotam principalmente o pastoreio para alimentação animal. Tal tipo de manejo representa um importante meio para o suprimento nutricional dos animais, a fim de proporcionar a constância da produção de leite (Costa et al., 2008).

A produção de leite é marcada por ter uma intensa complexidade e heterogeneidade em seus processos, devido a interação de diferentes parâmetros como ambientais, biológicos, econômicos e socioculturais (Lopes \& Lopes, 2001; Mattos, 
1977; Payá et al., 2007). Essas características demandam, portanto, a implementação de práticas de gestão que proporcionam a melhoria dos processos ligados ao setor leiteiro (Fagnani et al., 2014).

Notoriamente, a bovinocultura é uma atividade que requer atenção devido as suas singularidades ambientais, pois ao passo que torna o Brasil um dos maiores produtores de leite, contribui é também um dos maiores geradores de resíduos e demanda uma vultosa quantidade de água que abarque a dessedentação dos animais, assim como a higienização dos equipamentos das ordenhas e a instalação desses (Willers, 2014). Desse modo, é imprescindível que se busque políticas válidas ao assunto e instrumentos capazes de aumentar a qualidade do leite de maneira sustentável com objetivo de impedir possíveis intercorrências com a escassez de recursos hídricos e crescimento da atividade.

O leite é um produto de alta perecibilidade, característica que exige seu resfriamento no sentido de conservar sua qualidade até seu transporte à unidade de beneficiamento. Nesse sentido, faz-se necessário adotar protocolos técnicos que garantem o armazenamento adequado do leite em toda a cadeia produtiva (EMBRAPA, 2019), sendo a temperatura e o tempo de acondicionamento nos tanques resfriadores, fatores essenciais para a adequada conservação. Embora essencial, a refrigeração não é suficiente para garantir que o leite prossiga, pós processo, com boa qualidade, sendo importante também os cuidados com a saúde animal e as condições sanitárias antes, durante e depois do processo de ordenha - higiene e desinfecção do ambiente de produção, utensílios, equipamentos e veículo transportador (Brasil, 2018).

A Instrução Normativa (IN) n 77, de 26 de novembro de 2018 (Brasil, 2018) estabelece os critérios e procedimentos para a produção, acondicionamento, conservação, transporte, seleção e recepção do leite cru em indústrias, sendo uma importante ferramenta para o controle e garantia de qualidade na fazenda leiteira.

Segundo Vallin et al. (2009) os principais meios de contaminação microbiológica do leite nas fazendas são a superfície e a água residual dos latões e tanques de refrigeração, e tetos mal higienizados. Cumpre destacar que as análises acuradas da higienização dos tanques de refrigeração suscitam debates acerca de novos métodos de limpeza e conservação tanto do invólucro, quanto do leite, tornando-se primordial para qualidade do leite, que preconiza a sustentabilidade do meio ambiente.A contagem e determinação de microrganismos são fundamentais, sendo sua detecção e enumeração empregadas tanto para o controle da qualidade do leite, como da eficiência das práticas de sanitização de equipamentos e utensílios durante a produção e beneficiamento do produto (Chapaval, 2000).

O Comitê de Equipamentos do Conselho Brasileiro e Qualidade do Leite (CBQL) preconiza, dentre outras coisas, boas práticas de higienização dos tanques de refrigeração empregados na produção leiteira, orientando cuidados diretamente aplicáveis na rotina de limpeza e manutenção dos equipamentos. As principais orientações do CBQL são baseadas em aspectos químicos, a partir de análises desses deve-se determinar a quantidade de detergente necessária a ser utilizada e os procedimentos de enxágue do tanque - utilizando sempre a concentração determinada pelo fabricante. Aspectos relacionados com a ação mecânica (esfregação ou turbulência), tempo de circulação ou esfregação, ação química (concentração do detergente) e temperatura de início e fim de processo são importantes para a correta limpeza dos equipamentos (Alvares, 2010).

Portanto, a presente pesquisa teve como objetivo caracterizar as práticas atuais de higienização dos tanques de refrigeração de leite, de acordo com a sua localização geográfica na região semiárida do Rio Grande do Norte, bem como analisar o nível de conhecimento do responsável pela limpeza com relação às boas práticas preconizadas pelo CBQL.

\section{Metodologia}

\section{1 Área de Estudo}

O estudo foi desenvolvido em 27 fazendas leiteiras que possuíam tanques individuais para refrigeração do leite. As fazendas estavam sediadas em 14 municípios, distribuídos nas mesorregiões do Agreste, Central e Litoral do estado do Rio Grande do Norte. Os 27 tanques de refrigeração foram agrupados por municípios, de acordo com a Figura 1. 
Figura 1 - Mapa com a distribuição geográfica dos 27 tanques individuais de refrigeração do leite e os seus respectivos municípios-sede no estado do Rio Grande do Norte-RN.

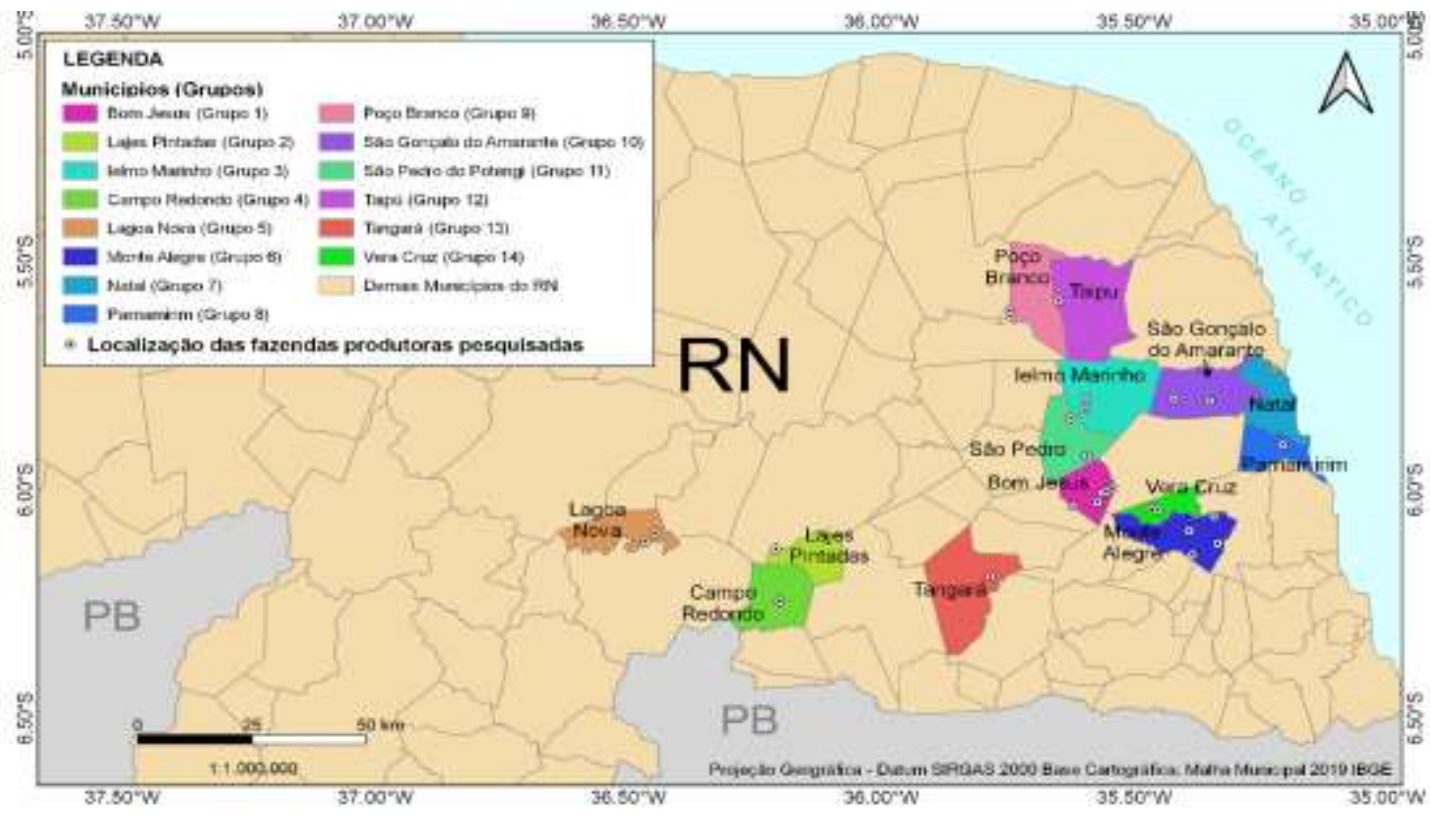

Fonte: Autores (2021).

\subsection{Condições de Armazenamento do Leite e Conhecimento de Limpeza do Produtor}

Foram realizadas visitas presenciais para verificar as condições de limpeza e a aplicação de questionário para o diagnóstico a respeito do nível de conhecimento do responsável pelos procedimentos de higiene do tanque.

Durante a visita foram registrados: I- o método de ordenha empregado para a obtenção do leite; II- o tipo de acessórios e substâncias ou compostos químicos usados para a limpeza do tanque; e, III- a origem da água utilizada no processo produtivo.

Os produtores foram indagados sobre o quanto conheciam e dominavam as boas práticas de limpeza e qual a importância da limpeza eficaz na rotina de uso, na opinião deles. Os questionamentos ocorreram por meio de entrevistas estruturadas. Finalmente, considerando a quantidade de respostas satisfatórias, foram atribuídas as seguintes classificações do nível de conhecimento dos produtores: escore $1=$ muito bom, escore 2 = bom, escore 3 = ruim.

\subsection{Análise Estatística}

Os tanques foram classificados quanto aos tipos de limpeza (vias neutras, alcalinas ou ácidas), acessórios utilizados, métodos de ordenha (manual e mecânica) e a origem da água (poço, adutora ou carro pipa).

Os dados das 27 fazendas leiteiras foram analisados mediante cálculo de médias e desvio padrão e as diferenças estatísticas pelo teste de Duncan (ao nível de significância de 5\%) com auxílio do software SAS versão 9.0. Dentre os escores, foram determinados por meio da análise de variância (ANOVA) se a diferença das médias de cada classe de dados era significativa, complementada com o índice de correlação de Spearman.

\section{Resultados e Discussão}

Na Tabela 1 são apresentados os resultados obtidos para as condições de limpeza com diferentes escores de conhecimento de limpeza em tanques. Foi verificada diferença estatística significativa (p-valor $<0,05)$ entre as variáveis expressas. Exceto para limpeza neutra. 
O p-valor é uma medida quantitativa para alimentar o processo de tomada de decisão como evidência, a partir dos dados coletados. Sendo o p-valor < 5\% indica uma evidência moderada de consistência dos dados (Ferreira; Patino, 2015).

Tabela 1 - Análise de condições de limpeza com diferentes escores de conhecimento de limpeza em tanques.

\begin{tabular}{lccc}
\multicolumn{1}{c}{ Variáveis } & \multicolumn{3}{c}{ Escore de Conhecimento de } \\
& 1 & 2 & 3 \\
Limpeza & & $1,85^{\mathrm{a}}$ & $2,23^{\mathrm{a}}$ \\
Escore Limpeza & $1,00^{\mathrm{b}}$ & $1,14^{\mathrm{a}}$ & $1,23^{\mathrm{a}}$ \\
Limpeza Neutra & $1,00^{\mathrm{a}}$ & $1,28^{\mathrm{ab}}$ & $1,84^{\mathrm{a}}$ \\
Limpeza & $1,42^{\mathrm{a}}$ & $1,57^{\mathrm{b}}$ & $2,00^{\mathrm{a}}$ \\
Alcalina & $1,42^{\mathrm{b}}$ & $1,71^{\mathrm{a}}$ & $2,00^{\mathrm{a}}$ \\
Limpeza Ácida & $1,28^{\mathrm{b}}$ & &
\end{tabular}

Nota: médias seguidas por letras distintas na linha diferem ( $\mathrm{p}$-valor $<0,05$ ) pelo teste de Duncan. Fonte: Autores (2021).

Houve diferença significativa em todas as variáveis, exceto na limpeza neutra. Em relação ao escore de limpeza dos 27 tanques, cerca de 50\% apresentaram escore 3 (ruim), 33,3\% bom e 16,67\% muito bom. Segundo a EMBRAPA, a correta limpeza do tanque é uma condição importante para definir a qualidade do leite proveniente de uma propriedade. Assim, um escore ruim remete a uma perda de índices de qualidade do produto.

Segundo a CBQL (2002), os procedimentos para a limpeza do equipamento consistem em cinco passos. Primeiramente, deve-se determinar a dureza da água, o teor de alcalinidade ativa e o teor de cloro mínimo necessários para a limpeza eficaz do equipamento (ordenha), os testes determinarão a quantidade necessária de detergente a ser utilizada; imediatamente após a ordenha enxaguar o sistema por completo com água morna a $40^{\circ} \mathrm{C}$, até a água ficar limpa, sem leite, não circular; em seguida preparar uma solução de detergente alcalino clorado $\left(\mathrm{pH}\right.$ maior que 11) e água com temperatura entre $70^{\circ}$ e $75^{\circ} \mathrm{C}$ - esta água deverá circular por 10 minutos e não pode-se deixar que a temperatura chegue a menos que $40^{\circ} \mathrm{C}$ no final da limpeza; drenar toda a solução da limpeza; e, por último, uma vez por semana (ou diariamente) circular uma solução de detergente ácido (pH menor que 3) à temperatura de 30 a $35^{\circ} \mathrm{C}$ (não pode ser superior a $60^{\circ} \mathrm{C}$ ) por 5 minutos - utilizar sempre a concentração determinada pelo fabricante.

A limpeza dos tanques de refrigeração é realizada por meio de 3 tipos, sendo esses: Limpeza neutra, alcalina e ácida , de acordo com o sanitizante utilizado, 23 proprietários utilizaram limpeza neutra, 11 limpeza alcalina e 7 limpezas ácidas, e apenas 7 proprietários utilizaram os três tipos de limpeza no mesmo tanque.

A sanitização é realizada por meio de desinfetante que reduz o número de agentes patógenos a um nível relativamente seguro. O uso de sanitizantes ajuda a manter a presença dos microrganismos no ambiente sob controle, combatendo o risco de contaminação cruzada e evitando a transmissão de doenças. Dos 27 proprietários, 7 utilizam métodos de sanitização e 20 não utilizaram nenhum método.

Na avaliação das médias, como mostra a Tabela 2, é possível observar que a maior média está atribuída ao escore de limpeza x conhecimento de limpeza. Esse fato ocorre visto que com o conhecimento da importância da limpeza, consequentemente seriam utilizados métodos mais eficientes de limpeza. 
Tabela 2 - Estatística descritiva dos dados de limpeza de tanques.

\begin{tabular}{ccccc} 
Variáveis & \multicolumn{4}{c}{ Limpeza } \\
& Média & Valor & Valor \\
Máximo & Mínimo & CV $(\%)$ \\
Escore Limpeza & 1,81 & 3,00 & 1,00 & 45,94 \\
Escore de conhecimento de & 2,22 & 3,00 & 1,00 & 38,12 \\
$\begin{array}{c}\text { Limpeza } \\
\text { Limpeza Neutra }\end{array}$ & 1,14 & 3,00 & 1,00 & 31,53 \\
Limpeza Alcalina & 1,59 & 3,00 & 1,00 & 31,44 \\
Limpeza Ácida & 1,74 & 3,00 & 1,00 & 25,65
\end{tabular}

Notas: CV= Coeficiente de variação. Fonte: Autores (2021).

Em relação ao conhecimento de limpeza dos tanques, 51,86\% dos produtores apresentaram conhecimento muito bom ou bom, e 48,15\% conhecimento ruim. Ou seja, o baixo conhecimento da importância da limpeza, pode afetar nos métodos utilizados e na eficácia dos mesmos (Pereira, 2011). A água utilizada para a limpeza dos tanques é obtida por meio de adutora, poço ou carro pipa, sendo grande parte de origem de poço (17 propriedades).

Na Figura 3, são apresentadas as correlações de Spearman entre escore de limpeza, conhecimento de limpeza, os tipos de limpeza: ácida, alcalina e neutra, uso de acessórios e sanitização. Entre o conhecimento de limpeza e limpeza alcalina há uma correlação positiva, indicando que conforme o conhecimento de limpeza aumenta, o efetivo de limpeza também se eleva.

Figura 3 - Correlação de Spearman entre as variáveis.

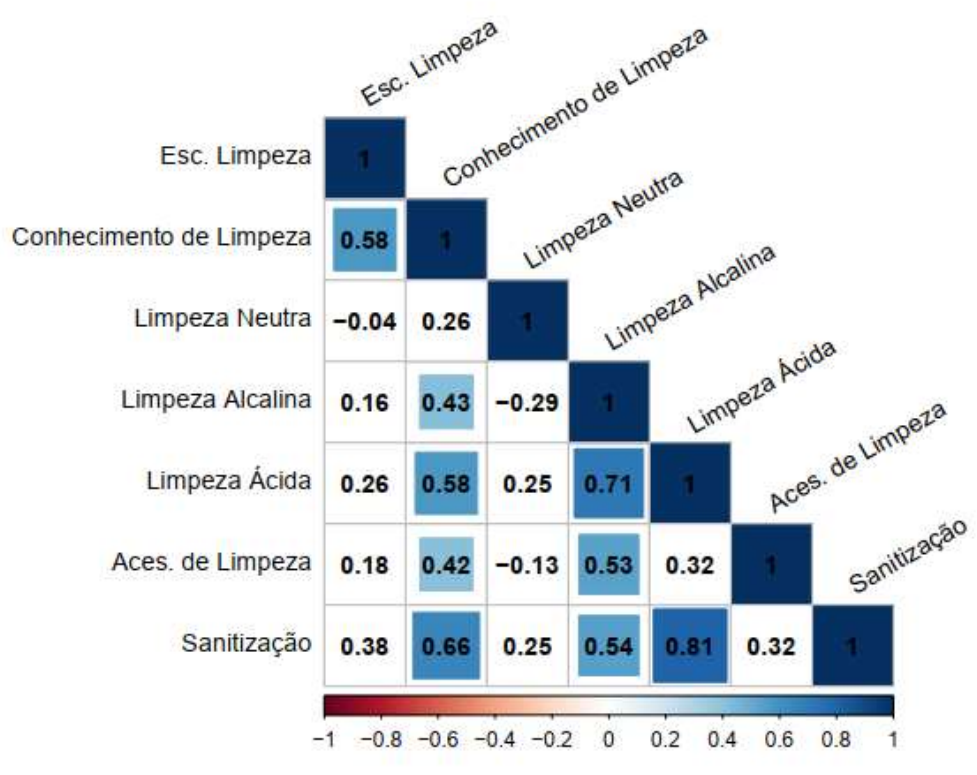

Fonte: Autores (2021).

Sendo assim, houve correlação entre o conhecimento do proprietário sobre a limpeza e a limpeza alcalina e ácida. Esse fato ocorreu provavelmente devido ao aumento da informação sobre limpeza o proprietário utilizou outras fontes de limpeza, pois foi observado que grande parte dos proprietários que utilizavam limpeza alcalina, também utilizavam a limpeza ácida. E quanto maior a utilização de limpeza ácida, maior a sanitização, conforme a correlação das variáveis. 


\section{Conclusão}

O presente estudo analisou a relação entre as práticas de higiene de tanques de refrigeração de leite e o conhecimento de produtores na região semiárida do Rio Grande do Norte sobre o tema.

Dentre os 27 tanques, 50\% apresentaram escore de limpeza 3 (ruim), 33,3\% bom e 16,67\% muito bom. Sobre o conhecimento de limpeza dos tanques, 51,86\% dos produtores apresentaram conhecimento muito bom ou bom, e 48,15\% conhecimento ruim. Apenas $25,93 \%$ dos proprietários utilizam métodos de sanitização.

É possível concluir que o conhecimento de limpeza do produtor é fundamental para garantir a qualidade do leite durante o processo de armazenamento. Além disso, quanto maior o conhecimento do produtor sobre a limpeza, melhor são os resultados da utilização dos métodos de limpeza.

Finalmente, as recomendações de procedimentos para limpeza de tanques de refrigeração de leite fornecidos pela CBQL não estão amplamente difundidas entre os produtores da região semiárida do Rio Grande do Norte. Um trabalho de ampla divulgação e conscientização ambiental podem garantir melhoria na qualidade do leite produzido no Estado, implicando em maior segurança sanitária para seu consumo e o consequente reforço na continuidade e sustentabilidade desse setor produtivo.

A qualidade da limpeza dos tanques no processo de produção leiteira pode ser fundamental para o sucesso de técnicas de reuso da água, em região que sofre de alta escassez de recursos hídricos. É necessário que se realizem mais trabalhos, vinculados ao reuso da água no processo produtivo do leite, já que a limpeza dos tanques é de extrema importância para a qualidade do produto.

\section{Referências}

Alvares, B. (2010). Higiene na ordenha. IV Congresso Brasileiro de Qualidade do Leite.

Anualpec (2019). Anuário da Pecuária Brasileira (20a ed.), Instituto FNP.

Araújo, T., Rangel, A., Lima, G., Peixoto, M., Urbano, S. \& Bezerra, J. (2018). Gir and Guzerat cow milk production and composition according to lactation stage, somatic cell count, physiological state and body condition. Acta Scientiarum. Animal Sciences, 65(3).

Brasil (2018). Ministério da Agricultura, Pecuária e Abastecimento. Instrução Normativa 77, de 26 de Novembro de 2018 . Estabelece os critérios e procedimentos para a produção, acondicionamento, conservação, transporte, seleção e recepção do leite cru em estabelecimentos registrados no serviço de inspeção oficial. Diário Oficial da União. Brasília, DF, 26 nov. 2018, Seção 1, p.10.

Campos, P., Rangel, A., Borba, L., Urbano, S., Novaes, L., Júnior, J., Sales, D. \& Aguiar, E. (2016, maio). Quality indicators of tank milk in different production systems of tropical regions. Semina: Ciências Agrárias, Londrina, PR, Brasil, 37.

Cbql (2002). Tanques de refrigeração: recomendações do comitê de equipamentos.Conselho Brasileiro de Qualidade do Leite. Quiron.

Chapaval, L. \& Piekarski, P. R. B (2000). Leite de qualidade: manejo reprodutivo, nutricional e sanitário. Aprenda Fácil.

Costa, C., Meirelles, P., Silva, J. \& Factori, M. (2008). Alternativas para contornar a estacionalidade de produção de forragens. Revista Veterinária e Zootecnia, $12(2)$.

Embrapa (2019). Protocolos técnicos garantem a manutenção da qualidade do leite em tanques de armazenamento refrigerado. Empresa Brasileira de Pesquisa Agropecuária.

Eurich, J., Neto, W. \& Rocha, P. H. (2016). Pecuária leiteira em uma colônia de agricultores familiares no município de Palmeira. Revista Ceres. Paraná, 63(4). 454-460.

Eurich, J., Neto, W. \& Rocha, P. H. (2013). Índices emergéticos de sustentabilidade da produção leiteira em uma propriedade de base familiar em Palmeira, Paraná, Brasil. Revista Ceres, 60(3):332-338.

Fagnani, R., Battaglini, A. P. P., Beloti, V., et al. (2014). Parâmetros físico-químicos e microbiológicos do leite em função da sazonalidade. Revista do Instituto de Laticínios Cândido Tostes. 69(3). 173-180.

Food and Agriculture Organization of the United Nations F. A. O. (2017). StatisticalYearbook. 1.

Lopes, M. A. \& Lopes, F. M. (2001). Custo de produção da pecuária e análise de rentabilidade da pecuária leiteira. Simpósio goiano (manejoo e nutrição de bovinos). Goiânia, Goiás.

Mattos, W. R. S. (1977). Sistemas de estabulação livre para bovinos. Simpósio (pecuária leiteira). 1123-1139. 
Research, Society and Development, v. 10, n. 13, e05101320192 2021

(CC BY 4.0) | ISSN 2525-3409 | DOI: http://dx.doi.org/10.33448/rsd-v10i13.20192

Patino, C. \& Ferreira, J. (2015). Qual a importância do cálculo do tamanho amostral? JBrasPneumol. 2016,42(2):162.

Payá, S., Simões, A., Filho, F., Silva, P. et al. (2007). Causas de variações não genéticas e interações estação x região em pesos de animais de rebanhos nelore mocho em áreas inclusas na região pecuária de leiteiras. ArchivesofVeterinary Science 12(2).

Pereira, D. (2011). Fatores Impactantes na Qualidade do Leite de Tanques Comunitários na Microrregião de Juiz de Fora (Dissertação de Mestrado Profissionalizante). Universidade Federal de Juiz de Fora, Juiz de Fora, Minas Gerais, Brasil.

Vallin, V., Beloti, V., Battaglini, A., Tamanini, R., Fagnani, R., Angela, H. \& Silva, L. (2009). Milk quality improvement after implantation of good manufacturing practices in milking in 19 cities of the central region of Paraná (Semina: CiênciasAgrárias, 30(1), $181-188$.

Willers, C. et al. (2014). Determination of indirect water consumption and suggestions for cleaner production initiatives for the milk-producing sector in a Brazilian middle-sized dairy farming. JournalofCleanerProduction, 72, 146-152. 10.1016/j.jclepro.2014.02.055. 